\title{
7
}

\section{The "Cultural Differences" Argument and Its Misconceptions: The Return of Medical Truth-Telling in China}

\author{
Jing-Bao Nie \\ 1 University of Otago \\ 2(Adjunct/Visiting) Hunan Normal University and Peking University \\ ${ }^{1}$ New Zealand \\ ${ }^{2}$ China
}

\section{Introduction}

Cultural differences are real and arresting. They are noted, discussed and debated in bioethics, as in contemporary social and political life in general. But cultural differences can be very tricky to interpret. Their factual status, moral meanings and political implications are rarely, if ever, as straightforward as they appear. Cultural differences can be seriously misconceived, misinterpreted, misrepresented and misused in various ways. Empirically problematic perceptions, ethically dubious judgments, and practically contentious resolutions can easily become entangled when considering matters of cultural difference. Many works on cross-cultural bioethics have often merely served to reinforce deeply rooted stereotypes and myths regarding both Western and non-Western cultures, especially the latter. A glaring example of such confusion is the appeal to perceived cultural differences as an ethical justification for rejecting those norms perceived as originating in the West and strongly advocated there - such as truth-telling by medical professionals, informed consent, patients' rights, women's rights and human rights in general. It is argued and widely held in certain circles that such practices and values are irrelevant and inapplicable to non-Western societies and cultures.

In this paper, I will critically examine "the cultural differences" argument as it has been formulated against medical truth-telling in the Chinese context. I will demonstrate that, despite its popularity and apparent plausibility, the argument is seriously flawed both descriptively and normatively. Elsewhere, through comparisons between China and the West and supported by extensive primary Chinese materials, I have shown that direct disclosure is far from culturally alien to China and that, on the contrary, there was once a long, though forgotten, tradition of medical truth-telling in China (Nie 2011: Chapter 6). Here, I argue that, even if medical truth-telling were culturally alien to China, as usually assumed, ethical imperatives exist to reform the contemporary mainstream Chinese practice of nondisclosure or indirect disclosure through family members. Moreover, I will offer a Confucian defence of truth-telling as a fundamental ethical principle and a cardinal personal and social virtue which physicians would do well to take seriously. In the process, I expose some common intellectual barriers to cross-cultural understanding: dichotomizing different 
cultures as "radical others" to one another, promoting the tyranny of existing cultural practices, and obscuring the real ethical issues at stake. To put the matter positively, I seek to present the elements of a more adequate cross-cultural bioethics or a "transcultural bioethics" - an ethics that resists cultural stereotypes, upholds the primacy of morality, and acknowledges the richness, openness and internal heterogeneity of medical ethics in every culture, whether in China or elsewhere.

\section{The "cultural differences" argument}

It is known far and wide that, in sharp contrast to most Western countries where truthfulness constitutes an essential, even legally required, element of good medical practice, medical professionals in contemporary China (including Hong Kong and Taiwan) customarily withhold from patients crucial information about terminal illnesses such as cancer. Any information given out is usually restricted to family members only, and is often given in an overtly paternalist manner (e.g., Kleinman 1988: 152, Li and Chou 1997, Pang 1998, 1999, Tse, Chong and Fob 2003, Fan and Li 2004, Tang and Lee 2004, Zhu 2005, Zeng, Li, Chen and Fang 2007, Tang et al. 2008).

This situation is not restricted to China. Nondisclosure or indirect disclosure through family members is the mainstream practice in other Asian countries such as Japan and Nepal, as well as in other parts of the world such as the Middle East and Eastern and Southern Europe (e.g. Surbone 1992, Mitsuya 1997, Gongal et al. 2006, Mobereek et al 2008). In different countries or within different ethnic groups within the same country, patients suffering from cancer and other terminal illnesses receive very different levels of information about their diagnosis, prognosis, and therapeutic options (e.g. Macklin 1999, Mitchell 1998, Mystakidou et al. 2004, Tuckett 2004, Hancock et al. 2007, Surbone 2006, 2008). As the title of an editorial by an Italian physician in the journal Support Care Cancer characterizes it, there is a "persisting difference in truth telling throughout the world" (Surbone 2004).

According to more recent literature, although "there is a shift in truth-telling attitudes and practice toward greater disclosure of diagnosis to cancer patients worldwide", "partial and nondisclosure is still common in many cultures that are centered on family and community values" (Surbone 2008, 237). Thus this striking cultural difference-direct disclosure in most Western countries vs. non-disclosure or indirect disclosure in most non-Western societiesis still prevalent in the twenty-first century.

It is from acknowledging this cultural divide that the "cultural differences" view, that opposes medical truth-telling in non-Western societies like China, has taken root. Two Chinese medical ethicists put the issue succinctly: "In contrast [with the West], Chinese medical ethics, even today, in theory and in practice, remains committed to hiding the truth as well as to lying when necessary to achieve the family's view of the best interests of the patient" (Fan and Li 2004, 180). Direct truth-telling - the so-called "Western individualistic mode" - is defined as being culturally alien to China and therefore morally unsound because it violates so-called "Chinese familial values".

In Japan, similar arguments have been put forward to reject medical truth-telling and replace it by a family-centered style of informed consent. A major rationale behind the distinction holds that the construal of the self in Japanese and Western culture is to be defined as "interdependent vs. independent" respectively, or, to put it another way, in terms of the family vs. the individual (Akabayashi and Slingsby 2006). 
The cultural differences argument against medical truth-telling can take a number of different forms. In the Chinese context, one common argument, in the form of a syllogism, goes like this:

Major premise: Different cultural norms and practices ought to be respected and maintained; Minor premise: In contrast to the Western practice of direct disclosure regarding terminal illness, the cultural norm in China is nondisclosure or indirect disclosure through family members;

Conclusion: Therefore, medical professionals should refrain from telling Chinese patients the truth about their terminal illness.

A more sophistical version of the argument goes thus:

First premise: Different cultural norms and practices ought to be respected and maintained;

Second premise: Chinese and Western cultures are fundamentally and radically different from each other;

Third premise: Truth-telling is the Western cultural norm and is founded on individualistic Western culture;

Fourth premise: Nondisclosure or indirect disclosure through family members is the Chinese cultural norm and is founded on family-oriented Chinese culture;

Conclusion: Therefore, nondisclosure or indirect disclosure through family members should be maintained and the practice of medical truth-telling rejected in China.

Whatever form it takes, the cultural differences argument consists of two core claims-one descriptive and the other normative. The empirical or descriptive claim generalizes secrecy and lying to the sick and dying as the representative and authentic cultural norm for Chinese. The normative claim insists the practice of nondisclosure should be maintained in order to respect perceived cultural differences. The descriptive claim is more widely held than the normative one: those who subscribe to the normative claim always found their position on the descriptive claim. Yet, those who accept the descriptive claim do not necessarily agree with the normative claim; they are thus free to take an ethical position against nondisclosure or indirect disclosure.

\section{The current debate in China}

Defying its contemporary stereotype as a monolithic, changeless nation or (in the famous metaphor of Napoleon) a "sleeping lion", China has always been in a state of flux. In the past three or so decades - a period designated by the Chinese authorities as one of "reform and openness" - the enormous social and economic transformations undergone by China have had a profound impact on the history of both China and the world. On the medical front, the patient-physician relationship, including the handling of medical information relating to incurable and terminal diseases, has undergone a comparable "revolution". In the 1980s when I was a medical student and intern in China, it was standard practice that patients were never told directly about their terminal illness. We were instructed to conceal such a diagnosis and even lie to the sick and dying - for instance, not to write the Chinese character for cancer, ai, on the patient's card, but the English abbreviation $\mathrm{Ca}$. This cloak of secrecy surrounding the terminally ill was (and still is) referred to by a special quasi-medical term - "protective medical treatment" (baohuxing yiliao).

Since the 1990s and especially the early 2000s, however, the practice of withholding crucial medical information has been challenged by patients, medical professionals, and 
the general public. An historic change is happening in China, a shift from secrecy and lying toward honest and direct disclosure. In 2008, thirteen hospitals throughout China and the premier Chinese journal Medicine and Philosophy jointly issued a series of documents on informed consent (Yixue Yu Zhexu 2008, 1-12). One of them is entitled "Guiding Principles on Truth-telling to and Consent from Cancer Patients". While it promotes only partial disclosure and insists on the necessity of "appropriate confidentiality" (ibid, 7-8), this document indicates that the Chinese debate on the issue has subtly shifted from whether patients should be told about their condition to when and how they should be best informed.

In many ways, the Chinese debate closely resembles the Western debate of the 1960s and 1970s. As a matter of course, advocates of honest and direct disclosure take up the language of rights - the right of the patient to know and decide. They also call attention to the damage done by secrecy and concealing the truth from patients, as well as the benefits of honest communication for both patients and physicians. On the other side of the debate, defenders of nondisclosure, especially medical professionals and family members, emphasize the duty to protect patients and, at least, to avoid doing harm. It is assumed that the communication of complex and negative medical information is bad for patients' morale, if not beyond their intelligence. It has often been asserted, not only in the mass media but also in the medical and academic literature, that telling the truth about terminal illness frightens and depresses patients, deprives them of hope, and may even shorten their lives. It has been circulated that young women are more vulnerable than other groups and are more likely to commit suicide after learning of a negative prognosis.

The Chinese debate differs in one salient area from that conducted in the West several decades ago: the issue of cultural differences. A common argument invoked to oppose medical truth-telling in China lies in the appeal to cultural differences, in particular to Chinese values and cultural context. Indeed, the invoking of the cultural argument raises a number of questions regarding the current Chinese trend to honest and open disclosure. Is this new development merely an aping of the contemporary Western norm? Is it a consequence of Western cultural hegemony or even of bioethical imperialism? More fundamentally, is this current shift in attitudes merely a change of fashion or is it based on sound moral foundations? If the cultural differences argument against medical truth-telling in China is valid, then current efforts to reform the still widespread practice of secrecy and lying to the sick and dying are heading in the wrong direction.

But the argument against this reform is seriously flawed. In what follows, I reveal and discuss a number of empirical and normative problems with this argument, however appealing it may be on the surface.

\section{Dicthotomizing east and west}

The cultural differences argument is anchored in and perpetuates a deeply rooted and still prevalent habit of thought: the dichotomizing of the West and the non-West as "radical others" to one another (for a critical examination of what can be called the "fallacy of dichotomizing cultures," see Nie 2011, especially Chapters 1 and 2). In bioethics, this polarization of East and West is manifested in the popular but specious idea of "Western individualist bioethics" vs. "Asian communitarian bioethics" (Nie 2007). According to this way of thinking, the dominant practice or official position of a given culture or social group is deemed the authentic representative of the culture or social group concerned. And the differences between and among cultures are perceived to be radical, 
fundamental, and largely incompatible with each other. As a result, the actual richness and great internal plurality of a given culture and the complexity of cultural differences within and between different groups are oversimplified and all too often seriously distorted.

Drawing on and perpetuating this cultural dichotomy, the cultural differences argument against medical truth-telling in the Chinese context has crudely distorted the historical and socio-cultural realities of both China and the West. As the first part of my comparative study of medical truth-telling has uncovered (Nie 2011, Chapter 6), historically speaking, it is simply incorrect to claim that truth-telling is the representative Western cultural norm while it is culturally alien to China. Far from being an age-old cultural tradition, in the West medical truth-telling did not become the accepted standard until the 1970s or even later - it has a history of a few decades only. And, on the other side, totally contrary to what has been universally assumed and presented both inside and outside China, the traditional practice and norm of Chinese culture and medical ethics was for physicians to disclose their diagnosis and prognosis of terminal illness truthfully and directly to patients. A great deal of primary historical material, including the biographies of ancient medical sages and hundreds of celebrated physicians in different dynasties (Chen 1991[1723]), reveals a wellestablished Chinese tradition of medical truth-telling that dates back at least twenty-six centuries. Ironically, the contemporary mainstream Chinese practice of nondisclosure as a "historical" phenomenon has a great deal to do with an older Western norm of concealing medical information.

\section{Chinese patients want to know the truth}

Sociologically, the cultural differences view has assumed that Chinese patients are not only kept in ignorance of their condition, but even prefer things this way. However, in total contrast to this assumption, the great majority of Chinese people, like Westerners, want to know the truth about their medical condition if suffering from serious illness.

In a telephone survey of 2674 Chinese households conducted in Hong Kong in 1995, 95\% of 1138 interviewees aged between 18 and 65 indicated that they would prefer knowing their medical diagnosis, even if the outlook was grave. The same proportion said they would object if their family only was informed, while they themselves were not told. And $97 \%$ of respondents would want to know their prognosis. The researchers concluded that the patterns of preference shown by Chinese people in Hong Kong were "very similar to those reported in studies on Western populations" (Fielding and Hung 1996). Taiwanese cancer patients also expressed a strong preference for medical professionals to tell them the truth, even before informing relatives (Tang and Lee 2004).

The same is true of mainland Chinese. In the early 2000s, speaking to a class of about 60 students, mostly postgraduates, in one of the leading ethics programs in China (in Hunan Normal University located in Changsha, a central southern Chinese city), I asked if they would like to know the truth if they were diagnosed with a terminal illness. A large majority responded "yes" (about 50), and only a handful said "no".

Despite some deficiencies in sample selections and research design, many extensive surveys conducted throughout mainland China clearly indicate the preference of the great (or even overwhelming) majority of Chinese patients suffering from terminal illness to be fully apprised of the medical facts about their condition. A survey of 311 cancer patients in Guangzhou in southeast China found that $72.99 \%$ believed that patients should be fully 
informed; $24.12 \%$ responded that the decision should depend on the wishes of the patients themselves; and only $2.89 \%$ thought that patients should not be told about their cancer diagnosis (Huang, Wang, Zhang, Lü and Li 2001). In a survey conducted in Shenyang, northeast China, involving 198 hospitalized elderly cancer patients and 312 family members, $94 \%$ of patients and $82.7 \%$ of family members considered it essential for the truth to be told about their terminal illness, and $97 \%$ of patients and $90.4 \%$ of family members believed that the sharing of accurate medical information would improve the outcomes of treatment (Gao, Zou and Yang 2006). Another survey of 302 cancer patients in Wuhan, central South China, concluded that, in general, cancer patients are very keen to know the truth about their illness and that the practice of "protective treatment" had resulted in distrust of medical professionals and increased concerns about the seriousness of their condition (Zeng, Zhou, Hong, Xiang, and Fang 2008).

However, the cultural difference view is accurate on one point - in China, most medical professionals and the majority of family members are unwilling to inform patients truthfully (see the survey results presented below). Interestingly, when they were asked whether or not they would like to know the truth if they were themselves had been diagnosed with terminal illness, the great majority said they would want to know. A survey conducted in 2004 among 180 nurses in Shandong in Northeast coastal China showed that, when imagining themselves as patients, they would prefer to be informed even though, as medical professionals, they would hesitate to tell the truth to their own patients (Zhu 2005, 73). When the nurses put themselves in their patients' shoes, the overwhelming majority of them, $92.6 \%$, preferred to know the diagnosis and prognosis of severe and terminal illness. However, when asked whether they as nurses should inform their patients about their adverse medical conditions, $71.6 \%$ said that they would withhold the truth. When asked to imagine themselves as patients' family members, only $2.5 \%$ would speak directly and immediately, $69.1 \%$ would choose to tell the truth after prevaricating for a time, and $28.4 \%$ would not disclose the condition in any circumstances (Ibid). A survey of 634 doctors and nurses, conducted in Wuhan, again illustrates that medical professionals are reluctant to speak candidly about cancer; that patients are aware of that they have insufficient knowledge about their medical condition; and that physicians are inclined to let family members, rather than patients, make important decisions (Zeng, Li, Chen, and Fang 2007).

As presented in the second section of this chapter, there are signs that the attitudes of mainland Chinese medical professionals are changing. In 2009, lecturing to a class of 50 medical students at Peking University Health Science Centre, a leading medical school in China located in Beijing, I asked the class whether they would tell patients about their diagnosis and prognosis of terminal illness. The great majority answered "yes" by raising their hands.

Other surveys confirm the disparity between patients' wishes on the one hand and the reluctance of family members on the other. In a survey of 175 patients and 238 family members visiting a hospital clinic in Beijing (He, Wang, Tian, Zhou and Wang 2009), 42\% of patients wanted to be told immediately after a diagnosis of cancer was confirmed, $31.4 \%$ wanted both patients and family members to be told together, and $26.3 \%$ preferred that only family members be informed. However, only $2.1 \%$ of family members wanted the diagnosis to be communicated directly to the patient - although $16.4 \%$ wanted both patients and family members to be told. The contrasts in this survey are stark: whereas nearly three quarters of patients wanted to be informed, either alone or with family members, more than 
three quarters of family members preferred that doctors inform them alone. In another survey of 194 family members of recently diagnosed and hospitalized cancer patients, $57.7 \%$ disagreed and $42.3 \%$ agreed that patients should be told (Sun, Li, Sun and Chang 2007). A further survey of 382 patients and 482 relatives in Chengdu, Southwestern China, indicates that cancer patients were more likely than family members to believe that patients should be informed (early stage, $90.8 \%$ vs $69.9 \%$; terminal stage, $60.5 \%$ vs $34.4 \%$ ) and that most participants preferred being told immediately after the diagnosis (Jiang, Li and Li et al. 2007).

One ethical question that arises from the disagreement between patients, their families, and health care providers, disclosed by these studies is - what should be done when patients want to know about their condition but medical professionals and relatives prefer to withhold information and even lie to them? In Chinese culture, the Golden Rule taught by Confucius is widely known and respected: "Do not impose on others what you do not wish for yourself" (jishuo buyu, wushi yuren). If the general preference of Chinese people for knowing the truth about terminal illness is interpreted as a wish not be lied to or to remain in ignorance, then, according to the Golden Rule, it is ethically unacceptable for medical professionals and relatives to impose on patients what they consider to be in the patients' best interests, regardless of what patients themselves prefer.

Another ethical question arises over the significant proportion of patients who prefer not to know about their prognosis. The short answer is that one should not impose the unpalatable truth upon this group. To ignore the wish not to know is as wrong as dismissing the desire to know. Perhaps pre-diagnosis informed consent is required to address this.

\section{Harms done by secrecy and untruthfulness}

As Tolstoy's The Death of Ivan Ilyich and Solzhenitsyn's Cancer Ward so vividly illustrate, patients can often sense the seriousness of their illness even though both medical professionals and relatives strive to keep the truth from them. My own experience as an intern at a Chinese county hospital in the 1980s confirms the reality of this instinctive awareness of their condition by patients. In fact, a major practical difficulty of hiding the truth in these circumstances is that it is almost impossible to carry out successfully. Humans communicate with each other not only through language, but also through their social context, body language, and by many other means. The specialised wards and hospitals that patients find themselves in, and the gestures of medical professionals, relatives and friends can easily reveal the truth, despite all efforts to hide it. For the patients concerned, whatever others may tell them, the secrecy surrounding their treatment reveals a truth of paramount importance - their illness is serious.

Even if it were feasible to hide the truth from patients, the practice of nondisclosure-the norm in China today-should be reversed because it is harmful to patients. On the one hand, the advocates of nondisclosure have offered no compelling evidence of its benefits for patients or their families. On the other hand, they often downplay or ignore the enormous harm that the practice of nondisclosure and evasion has caused to patients, families, the medical profession, and society at large. In addition to dismissing patients' wish to know, the practice of nondisclosure increases the feelings of abandonment of those suffering from terminal illness and undermines the bonds of social trust, in particular those between patients and medical professionals. 
For the cultural differences argument, the ethical rationale for disclosure turns on the question of individual rights and personal autonomy. The norm of medical truth-telling is thus arguably not applicable to those societies and cultures where the language of individual rights and autonomy is largely absent. It is true that, politically, the shift from nondisclosure to disclosure that occurred in most Western countries around the 1970s had a great deal to do with the patients' rights movement. And, in bioethics, disclosure and informed consent are often theoretically justified out of respect for the patient's autonomy, a leading principle in the discipline. However, it is a mistake to regard the ethical rationale for direct disclosure as wholly based on the notions of individual rights and autonomy. There are other sound ethical reasons for direct disclosure-for instance, the principle of beneficence, a fundamental value for almost every healing system and medical ethics tradition worldwide.

Although often overlooked in cross-cultural discussions of truth-telling and informed consent, a major factor in the historical shift toward disclosure in the West was the practical necessity for effective (but not overly aggressive) therapeutic intervention. Jay Katz's The Silent World of Doctor and Patient, a classic of bioethics, has highlighted this crucial point. The practice of truth-telling and informed consent is grounded not only in the principle of autonomy or self-determination, but also in good therapeutic management in face of the problem of uncertainty in medicine and the new challenges that have arisen in caring for seriously ill and dying patients. Nondisclosure and untruthfulness are not ethically justifiable because "[t]he iatrogenic deprivation of information makes a powerful contribution to patients' sense of abandonment." (Ibid, 212)

Doctors' ready retreat behind silence-apparent to patients by doctors' demeanor when they keep most of their thoughts to themselves, deprive patients of vital information, or pat patients on the back and assure them that everything will be all right and they need not worry - makes patients feel disregarded, ignored, patronized, and dismissed. (Ibid, 209-210) In the words of two other authors, "Tacitly to impose silence, denial, deception, and isolation upon the dying patient may itself cause suffering and bring about bereavement of the dying, a state of premortem loneliness, emotional abandonment, and withdrawn interest" (cited in Katz 2002: 222). The practice of nondisclosure thus serves medical professionals' interests more than those of patients. Disclosure and informed consent, on the other hand, "seek to protect patients from the ravages and pain of abandonment" (Ibid, 208). In the late nineteenth century, Tolstoy imaginatively rendered the detrimental effects of lying to the patient with terminal illness:

Ivan Ilyich suffered most of all from the lie, the lie, for some reason, everyone accepted, that he was not dying but was simply ill, and that if he stayed calm and underwent treatment he could expect good results. Yet he knew that regardless of what was done, all he could expect was more agonizing suffering and death. And he was tortured by this lie, tortured by the fact that they refused to acknowledge what he and everyone else knew, that they wanted to lie about his horrible condition and to force him to become a part of that lie. This lie, a lie perpetrated on the eve of his death, a lie that was bound to degrade the awesome, solemn act of his dying to the level of their social calls, their draperies, and the sturgeon they ate for dinner, was an excruciating torture for Ivan Ilyich. And, oddly enough, many times when they were going through their acts with him he came within a hairbreadth of shouting: "Stop your lying! You and I know that I'm dying, so at least stop lying!" (Tolstoy 1981, 102-103) 
Acknowledging to patients the seriousness of their medical condition may not be caring or healing in itself (although one could argue that it is), but it is at least the starting point for any good caring and healing regime. Medical professionals and other caregivers may lack the power to truly relieve the suffering of gravely ill and dying patients, but, as Ivan Ilyich urged, they can "at least stop lying".

Those who defend the practice of nondisclosure in China may contest that Chinese patients do not feel the abandonment, loneliness and agony that Ivan Ilyich or Western patients experienced when deprived of critical medical information. But, unless convincing empirical evidence is provided for this imagined cultural difference, one must assume that Chinese patients do not differ radically from their counterparts in the West in this regard.

The major concern in contemporary China, as in the West a few decades ago, is that open and direct disclosure may harm patients. Yet, in Western countries where medical truthtelling has now become firmly established it has been shown that concerns over the presumed psychological and physical harms to patients are in most cases unfounded. And it need hardly be said that such paternalistic attitudes seriously underestimate the intelligence, resilience and resolve of patients suffering from terminal illness in dealing with the realities of death and dying.

Lying has a further serious detrimental effect - the harm done to the patient-physician relationship. Social trust is the foundation of any good communal life. Lying to patients undermines their trust in medical professionals, just as lying in public life does lethal damage to the sustaining and nourishing of social trust. So nondisclosure and untruthfulness can hardly be justified by either "individualistic" or "communitarian" values.

\section{The question of family}

As we have seen, a key element of the cultural difference view that defends the Chinese practice of nondisclosure stems from a highly legitimate and important concern - the interests and integrity of the family. However, a number of the assumptions and assertions involved in defending this concern are empirically problematic and ethically misleading. Although detailed discussion of the role of the family in relation to bioethics from a Chinese-Western comparative perspective needs much more space, I wish to at least raise a few questions on the subject here.

Firstly, based on the popular dichotomy of China and the West as "radical others", the cultural differences argument posits a cross-cultural distinction, asserting that the family is central or even unique in Chinese culture but not so in the West. Those who would make this assertion are very selective and arbitrary in their choice ofcultural traditions within China and the West. Several major Chinese schools of thought and socio-political movements such as Daoism, Moism, the New Culture Movement in the early twentieth century and Chinese socialism - both in its ideology and in its political-economic system have all challenged the primacy of the family. At the same time, the essential role of the family in Western civilization (e.g., in Judeo-Christian tradition) as well as in Western bioethics has very often been downplayed and even dismissed. The truth is that, both as an essential social institution and as a cardinal moral value, the family has always been a vital element of any society or culture, whether in the East or in the West. 
Secondly, the practice of nondisclosure in China has been attributed to the value placed by Confucianism on the primacy of the family. Yet, as I showed elsewhere (Nie 2011), the wellestablished Chinese tradition of open and direct disclosure on medical matters was endorsed by one of the key Confucian moral ideals, that of cheng (truthfulness, sincerity).

Thirdly and most importantly, the argument about the family assumes that the practice of nondisclosure or indirect disclosure is more beneficial to the family than that of direct disclosure. However, there is no empirical evidence to support this. Secrecy and lying can be very harmful to family relationships as vividly portrayed, once again, in Tolstoy's Death of Ivan Illich. On the contrary, a strong case can be made that direct disclosure may better serve families affected, and family values, in than nondisclosure and deceit.

Drawing on the classic work of Sissela Bok (1989 [1978]), who condemns deception in public life, including lying to dying patients, as both ethically unjustifiable and practically harmful, some Western scholars have challenged the "cultural difference" view of truth-telling to the sick and dying in the Chinese context (e.g. Wear 2007). Still, we are warned to "studiously avoid presuming to take a firm stand" on lobbying for truth-telling as a general rule in Chinese society because the available data allegedly do not give a clear picture on two crucial points at the heart of the realted ethical dilemma: what Chinese patients typically want, and whether medical truth-telling will undermine the traditional Chinese family (Ibid).

However, as discussed above, we do have reliable data on the preference of the majority of Chinese to know the truth about terminal illness. As for the relationship between truthtelling and the family, the practice of direct disclosure in the West over the past several decades suggests that disclosure in itself does not necessarily harm the family as a social institution or as a locus of moral value. Truth-telling can empower family members to better support dying patients, attend to the needs and wellbeing of their loved ones, and diminish the feelings of abandonment and loneliness experienced by their suffering relative. In such difficult times when, as a Chinese saying expresses it, the whole family suffers if a single member is in pain (yiren xiangyu, mandang bule), truth-telling can strengthen, rather than weaken, the bonds of love and interdependence among family members.

\section{The Confucian morality of truthfulness and its ethical implication for medical practice}

The contemporary Chinese practice of non-disclosure or indirect disclosure has been presented and argued to be justifiable and preferable according to Confucianism (e.g. Fan and Li 2004). However, this interpretation of Confucianism is historically groundless (see Nie 2011: Chapter 6) and normatively wrong and misleading. In other words, the contemporary dominant - though challenged - practice in China cannot be justified by the ethical principles and ideals of major Chinese moral, political and spiritual traditions such as Confucianism.

In Confucianism, the highest moral ideals or principles are ren (humanity, humaneness), yi (righteousness) and $l i$ (the correct performance of rites), although scholars disagree about which has primacy (for a discussion of Confucian professional ethics of medicine, see Nie 2011: Chapters 11 and 12). While chengxin (truthfulness, honesty, trustworthiness or sincerity), another virtue highly regarded in Confucianism, is often used as a single phrase in modern Chinese, in classical Chinese cheng and xin are two closely related but different concepts, especially in Confucian tradition. Confucius himself discussed xin frequently in 
the Analects. While it rarely appears in the Analects, cheng is a key term in Neo-Confucianism and in other two Confucian classics, The Great Learning and The Doctrine of the Means.

The necessity of acquiring xin is a major theme in the Analects. According to a contemporary Chinese scholar, the term - meaning honesty, faithfulness and truthfulness - appears at least 24 times in the "Bible of China" (Yang1980, 257). The other fundamental Confucian concepts of ren, $l i$ and yi appear 108, 74, and 24 times in the Analects respectively (Ibid, 221, 311, 291). Since the early Han Dynasty (c. the $2^{\text {nd }}$ century BCE) when Confucianism was established as the official ideology of the state, xin has been regarded as the fifth of the Five Cardinal Virtues (wuchang) of Confucianism. Confucius used the metaphor of the yoke or horse harness to illustrate the importance of honesty and truthfulness for both individuals and social life (II, 23):

The Master said, "I do not know how a man without truthfulness is to get on. How can a large carriage be made to go without the cross-bar for yoking the oxen to, or a small carriage without the arrangement for yoking the horses?" (Legge 1971 [1893], 153)

Confucius placed a very high value on xin, stating that "No human being can stand without truthfulness" (XII, 7) and, in The Great Learning (III, 3), "In communication with people, he [ie, the truthful person] abides in faithfulness."

While the term cheng (sincerity, authenticity or truthfulness) is rarely mentioned in the Analects, it is a crucial concept in other Confucian classics and for Confucianism in general. The term embodies a complex nexus of metaphysical, ethical, psychological, and spiritual meanings, as the following quote from The Doctrine of the Mean (XX,18) indicates:

Sincerity [truthfulness] is the way of Heaven. The attainment of sincerity is the way of men. He who possesses sincerity, is he who, without an effort, hits what is right, and apprehends, without the exercise of thought; - he is the sage who naturally and easily embodies the right way. He who attains to sincerity, is he who chooses what is good, and firmly holds it fast. (Legge 1971[1893], 413; emphasis original)

Philosophically, this passage is comparable to Kant's discussion of "the good will". Still, however sophisticated the ramifications of the term may be, at the most basic level, like xin, cheng equates to one of the most fundamental moral maxims endorsed by most if not all human societies and ethical systems: be honest and, at the very least, do not deceive.

It is important to point out that, while the ethical principle of truthfulness is essential for Confucianism, this value is not absolute. In certain situations, concealing the truth is certainly an acceptable course, even a praiseworthy one. According to a story in the Analects (XIII, 18):

The duke of Sheh [Ye], informed Confucius, saying, "Among us here there are those who may be styled upright [or just] in their conduct. If their father has stolen a sheep, they will bear witness to the fact."

Confucius said, "Among us, in our part of the country, those who are upright are different from this. The father conceals the misconduct of the son, and the son conceals the misconduct of the father. Uprightness [or justice] is to be found in this." (Legge 1971 [1893], 270).

In one of the early dialogues of Plato, Euthyphro, Socrates challenged a similar belief that it is right to indict one's father for committing manslaughter. Many commentators, ancient, modern and contemporary, have debated the rationale behind the position taken by Confucius here. For the purposes of our discussion, the point is that, in striking contrast to Kant's deontological ethics, truthfulness is not an absolute value in Confucianism. 
What are the implications of the Confucian morality of truthfulness for medical practice regarding whether medical professionals should tell the patients the dire diagnosis and prognosis? First and foremost, as a general maxim for medical practice, healthcare professionals should abide by truthfulness as strictly as they can, following the consensus established by traditional Chinese medical ethics over the centuries. To deceive patients for motives of personal gain is always absolutely wrong and morally corrupt. Even when delivering painful news, as in the diagnosis and prognosis of terminal illness, truthfulness should not be easily set aside and medical practitioners should practice open and direct disclosure as a general rule, following the norm of the ancient Chinese medical sages.

Moreover, following the example of the systematic modern Chinese text on the professional ethics of medicine (Nie 2011: Chapter 6), a careful distinction should be made between lying (or deception) and concealing the truth. Ethically, there is a subtle but significant difference between these two; in the words of a Chinese idiom, "an error the breadth of a single hair can lead someone astray by a thousand miles".

The principle of truthfulness should be breached only in exceptional circumstances, such as when complete candour would lead to serious danger for the patient, such as confirmed risk of suicide due to breaking bad news. For Confucian medical ethics the highest ideal is ren, as articulated in the ethical definition of healing: "medicine as the art of humanity or humaneness". Nevertheless, the burden of proof should fall on those who believe that the principle of open and direct disclosure should be breached in order to avoid perceived risks to the patient. I have presented overwhelming evidence in this chapter that the great majority of Chinese patients want information about their medical condition. And we have seen that a conspiracy of silence or outright deception by family members and medical professionals can do great harm to patients. So those cases in which the truth needs to be concealed are likely to be rare. Cases where patients need to be deceived should be even rarer.

Yet, while most Chinese patients would prefer to know the truth about their medical condition, there is still a significant proportion of patients who prefer to be kept in ignorance about their prognosis. This raises a moral question as well as a medical challenge. As mentioned in Section 5, the short answer is that one should not impose the unpalatable truth upon this group; and to ignore a patient's wish not to know is as wrong as dismissing their legitimate desire to know. From a cross-cultural perspective, patients who subscribe to the "ignorance is bliss" mentality can be found not only in China but also in the West. On this point, it is also worth pointing out that, as far as Confucianism is concerned, the concept of cheng includes a criticism and even a condemnation of self-deception.

The radical level of disagreement revealed in the hospital survey results cited above provides evidence of a genuine moral dilemma for contemporary Chinese: that is, as discussed at the end of Section 5, what should be done when patients want to know the truth about their condition but medical professionals and relatives prefer to withhold information and even lie to them? According to the Golden Rule in Confucianism, "Do not impose on others what you do not wish for yourself," medical professionals should not obstruct the wish of patients in order to achieve what they believe to be in the best interest of patients.

Placing the onus of disclosure on family members in cases of terminal illness, a practice that is widespread in China and favourably endorsed by the advocates of the cultural differences argument, raises additional ethical questions. For instance, is this really in the 
patient's best interests, or for the convenience of medical professionals? Telling patients the truth about their serious condition is an art; however caring and experienced he or she may be, no physician will be perfect at this. As the 1847 Code of Ethics of the American Medical Association recommends, it is not ethically sound for physicians to delegate this difficult task wholly to family members. Apart from their obvious lack of systematic training in medicine and counselling, most importantly, lay relatives may lack the necessary professional and personal distance often critical for imparting sensitive information in an empathic way. Chinese medical professionals need to change their practice on this. Shunning a professional duty merely because of its difficulty is unacceptable, ethically and professionally. If the real motivation for "familist" practice is simply the convenience of medical professionals, then the practice clearly needs reform. For Chinese medical practitioners, the basic requirement of the Confucian medical ideal, "medicine as the art of humanity", is to fulfil their professional duties, however challenging they may be.

\section{The tyranny of culture vs. the primacy of morality}

Respecting perceived cultural differences constitutes a major ethical stumbling block to implementing the practice of direct and truthful medical disclosure in non-Western societies (and non-European groups within Western countries). By this logic, the current mainstream cultural practice is proffered as a sufficient ethical rationale to reject medical truth-telling. In other words, the "cultural difference" proponents attempt to bypass the moral difficulties involved by substituting statements about cultural practices for serious ethical examination. In this age of Western cultural hegemony, it is extremely important to respect different cultural practices, especially non-Western ones. However, an ethical dilemma arises when cultural practices conflict with moral imperatives. The cultural difference argument privileges cultural practices over ethical mandates; it implies, if not holds, that whatever is culturally authentic is automatically ethically defensible. This tyranny of culture over ethics can easily lead to moral relativism and even ethical nihilism. According to the logic of the cultural difference view, slavery in human history; gender discrimination and many other forms of discrimination, which are found in almost all human societies; the West's colonization of the non-Western world; the Third Reich in Germany; and foot-binding in Chinese history - to list just a few examples - are all ethically justifiable because all these practices were or still are culturally genuine and even unique.

More crucially, respecting cultural norms and practices can actually work against the fundamental values of a given culture and society. For both Confucianism and Daoism, the two major indigenous Chinese moral and political traditions, it is not existing cultural practices that should be privileged, but whatever is morally right. For Confucianism and Daoism, the most fundamental value is precisely the primacy of ethics and morality over existing social and cultural practices, rather than the other way around. The moral imperative of the Dao (Tao, literally "the Way") or the Tianming (the mandate of Heaven) is superior to the claims of any cultural and social practices, whether Western or Eastern. The basic task and highest calling of ethics is, first of all, to identify which socio-cultural practices are morally justifiable and which are not. 


\section{Conclusion}

Taking a universalist ethical position on human rights and patients' rights, other bioethicists have forcefully argued the importance of truth-telling and informed consent internationally, in China as well (Macklin 1999). This may be seen as a kind of outside perspective. In this paper, my stance is from the inside out.

My aim is not to dispute the existence of widely acknowledged cultural differences in China and the West regarding medical truth-telling. Rather, the key question for me is how this prima facie cultural difference-direct disclosure vs. non-disclosure or indirect disclosure - should be interpreted historically, sociologically and ethically. In particular, I have demonstrated that, despite its popularity and apparent plausibility, the cultural differences argument against medical truth-telling in China is seriously flawed at both the descriptive and normative levels. It has oversimplified and distorted both the historical and socio-cultural realities, including the role of family, in both China and the West. It has mis-presented and misinterpreted the standpoints of such major Chinese traditions as Confucianism on the subject. Historically, it has ignored the venerable Chinese tradition of direct truth-telling and, sociologically, it has dismissed the wishes of the great majority of Chinese patients who want to know the truth about their prospects. Ethically, it has obscured critical moral problems involved in nondisclosure and deception by medical professionals, and it promotes the tyranny of existing socio-cultural practices over ethics and acceptable morality.

Therefore, the contemporary Chinese practice of concealing the truth and even lying to patients about their terminal illness, no matter how widespread, ought to be critically examined, vigorously challenged, and systematically reformed. Culturally, the shift toward honest and direct disclosure now occurring in China is not so much -or at least not justfollowing a Western pathway, but constitutes a return to a neglected indigenous tradition (for a detailed discussion of this forgotten Chinese tradition, see Nie 2011, Chapter 6). More importantly, even if it were proven to be culturally alien to China as universally assumed, the norm of truth-telling should be instituted on the basis of the ethical imperatives presented in this paper.

As for cross-cultural bioethics, if I have appeared to argue that all cultures are fundamentally the same and that cultural differences do not matter, I would like to say that this is not my intention. My point is that Chinese and Western cultures are different, but not in the ways suggested by popular stereotypes, not in the sense of their being "radical others" to one another. As this study of medical truth-telling in China and other research projects have illustrated, Chinese-Western cultural differences are far more complicated, subtle, intriguing - and thus more difficult to grasp and articulate - than facile overgeneralizations. Rather than being homogenous and static, Chinese culture, like any other human culture, has always been internally heterogeneous, full of contradictory elements, changing over time, influenced by and borrowing elements from foreign cultures, open to new possibilities, and subject to ethical scrutiny and developing moral ideals. The complexity of cultural differences as indicated in medical truth-telling in China in comparison with the West calls for a more adequate cross-cultural bioethics or a "transcultural bioethics": an ethics that resists cultural stereotypes, cherishes the common humanity, upholds the primacy of morality, and acknowledges the richness, internal diversity, dynamism and openness of medical ethics in every culture, whether in China, 
the West or elsewhere (for these general points, see Nie 2005, 2007, 2009, and especially 2011).

\section{A Personal note}

I would like to end this paper on a personal note. In the late 1980s, the father of a former medical school classmate and good friend of mine was suffering the final stages of lung cancer. A psychiatrist himself, without any knowledge of the new practice of disclosure in the West, my friend informed his father of the diagnosis and prognosis - something his father's doctors and nurses never did. In taking this step, my friend set out bravely in defiance of the dominant social and medical norm of nondisclosure, and unknowingly travelled a way that ancient Chinese medical sages had walked more than twenty centuries ago. At the time, I should have questioned him further about his courageous decision to choose this unorthodox route. But our discussions were kept brief - after all, it is never easy to talk about the death of a loved one. Now it has become impossible for me to continue the dialogue. Having just celebrated his $31^{\text {th }}$ birthday, and when working as a visiting physician in Japan in 1994, my friend was hit by a car while riding a bicycle and died from his injuries.

This paper is humbly dedicated to Dr Zou Xinxin (1963-1994), a brilliant physician and friend. If only I could have had the benefit of his endorsement and criticism.

\section{Acknowledgements}

The expanded version of this chapter will be included in my forthcoming book, Medical Ethics in China: A Transcultural Interpretation, to be published by Routledge. This work is a part of a larger research project on medical ethics in China, financially supported by a University of Otago Research Grant. I am very grateful to Li Hongwen in Beijing for his research assistance in search of Chinese materials and Dr Paul Sorrell in Dunedin for his professional editing. Parts of materials have been presented as invited speeches at the $7^{\text {th }}$ Beijing Forum, at a symposium organized by Giuliana Fuscaldo, Lynn Gillam and Sarah Russell for the 10 $10^{\text {th }}$ World Congress of Bioethics, and at the second seminar of the New Zealand Ministry of Health Pacific Health Leadership. I gratefully acknowledge the organizers and the audiences of these events for their interest in my work and for their helpful questions and comments.

\section{References}

Akabayashi A. and B.T. Slingsby. (2006). Informed Consent Revisited: Japan and the U.S. American Journal of Bioethics, Vol. 6, No. 1(Jan-Feb 2006), pp.9-14, ISSN 1526-5161, eISSN 1536-0075.

Bok. S. (1978). Lying: Moral Choice in Public and Private Life. New York: Vintage Books. ISBN10: 0375705287, ISBN-13: 978-0375705281

Chen, Menglei. (1991). [1723]. Gujin Tushu Jicheng Yibu Quanlu (A Collection of Ancient and Modern Books, Section on Medicine), Book 12: General Discussions (Volumes 501520 in original), Beijing: People's Health Press. (In Chinese) 
Fan, R. and B. Li. (2004). Truth Telling in Medicine: The Confucian View. Journal of Medicine and Philosophy, Vol. 29, No.2, (April 2004), pp. 179-193, ISSN 0360-5310, eISSN 17445019 .

Fielding, R. and J. Hung. (1996). Preference for Information and Involvement in Decisions during Cancer Care among a Hong Kong Chinese Population. Psycho-, Oncology Vol. 5, No.4, (December 1996), pp. 321-329, ISSN: 1057-9249, eISSN 1099- 1611.

Gao, B., D. Zou, and L. Yang. (2006). A Study of Methods and Timing with Regard to Informing Elderly Cancer Patients. Nursing Journal of Chinese People's Liberation Army. No. 10. (in Chinese)

Gongal, R. P. Vaidya, R. Jha, O. Raijbhandary \& M. Watson. (2006).Informing patients about cancer in Nepal: what do people prefer. Palliative Medicine, Vol.20, No.4, (June 2006), pp. 471- 476, ISSN 0269-2163, eISSN 1477-030X.

Hancock, K. et al. (2007). Truth-telling in discussing prognosis in advanced life- limiting illness: a systematic review. Palliative Medicine, Vol. 21, No.6, (September 2007), pp. 507-517, ISSN 0269-2163, eISSN 1477-030X.

He, R., Y. Wang, Y. Tian, C. Zhou, H. Wang. (2009). The Preferences of Chinese Patients and their Relatives Regarding the Disclosure of Cancer Diagnoses. Chinese Journal of Clinical Oncology and Rehabilitation. No. 3. (in Chinese)

Hern, H.E. Jr., B.A. Koenig, L.J. Moore, \& P.A. Marshall. (1998). The Difference That Culture Can Make in End-of-Life Decision Making. Cambridge Quarterly of Healthcare Ethics Vol. 7, No.1,(Winter 1998), pp. 27-40, ISSN 0963-1801, eISSN 1469-2147.

Huang, X., X. Wang, Y. Zhang, B. Lü, and T. Li. (2001). Information Needs of Cancer Patients: Whether and How to Disclosure the Diagnosis of Cancer. Chinese Journal of Mental Health No. 4. (in Chinese)

Jiang, Y., C. Liu, J-Y Li, et al. (2007). Different attitudes of Chinese patients and their families toward truth telling of different stage of cancer. Psycho-Oncology, Vol. 16, No. 10, (October 2007), pp. 928-936, ISSN: 1057-9249, eISSN 1099-1611.

Jotkowitz, A., S. Click and B. Gezundheit. (2006). Truth-telling in a Culturally Divers World. Cancer Investigation 24:786-789.

Kagaw-Singer, M. and L.J. Blackhall. (2001). Negotiating Cross-Cultural Issues at the End of Life: "You Got to Go Where He Lives". Journal of American Medical Association,Vol. 286, No.23, (December 2001), pp. 2993-3001, ISSN 0098-7484, eISSN 1538-3598.

Katz, J. (2002) (first edition 1984). The Silent World of Doctor and Patient (with a new foreword by A. M. Capron). Baltimore and London: Johns Hopkins University Press. ISBN 978- 4020-8603-8, eISBN 978-4020-8604-5, Springer.

Kleinman, A. 1988. The Illness Narratives. New York: Basic Books. ISBN 0-465-03202-8, ISBN 0-465-03204-4. United States of America.

Legge, J. (tran) (1971) [1893], The Confucian Analects, The Great Learning and The Doctrine of the Mean, New York: Dove.

Li, S., and J-L Chou. (1997). Communication with the Cancer Patient in China. Annals of New York Academy of Sciences, Vol. 809,(February 1997), pp. 243-248 ISSN 0077-8923, eISSN 1749-6632.

Macklin, R. (1999). Against Relativism: Cultural Diversity and the Search for Ethical Universals in Medicine. New York and Oxford: Oxford University Press, ISBN 0-19-511632-J, NY. 
Mitchell. J. (1998). Cross-cultural Issues in the Disclosure of Cancer. Cancer Practice 6(3): 153160.

Moberireek A.F. et al. (2008). Information disclosure and decision-making: the Middle East versus the Far East and the West. Journal of Medical Ethics Vol.34, No.4, (April 2008), pp. 225-229, ISSN 0306-6800, eISSN 1473-4257.

Mystakidou, K., E. Parpa, E. Tsilika, E. Katsouda, and L. Vlahos. (2004). Cancer information disclosure in different culture context. Support Care Cancer, Vol. 12, No.3, (March 2004), pp. 147-154, ISSN 0941-4355, eISSN 1433-7339.

Nie, JB. (2011) (forthcoming). Medical Ethics in China: A Transcultural Interpretation. London and New York: Routledge.

Nie, JB. (2009). The Discourses of Practitioners in China. in Robert Baker and Larry McCullough, eds., The Cambridge World History of Medical Ethics, New York and London: Cambridge University Press. Chapter 21, pp. 335-344.

Nie, JB. (2007). The Specious Idea of an Asian Bioethics: Beyond Dichotomizing East and West, in R.E. Ashcroft, A. Dawson, H. Draper and J.R. McMillan, eds. Principles of Heath Care Ethics, Second Edition, London: John Wiley \& Sons. pp. 143-149.

Nie, JB. (2005). Behind the Silence: Chinese Voices on Abortion. Lanham and Oxford: Rowman \& Littlefield.

Pang, M.S. (1998). Information Disclosure: The Moral Experience of Nurses in China. Nursing Ethics, Vol. 5, No.4, (July 1998), pp.347-361, ISSN 0969-7330, eISSN 14770989.

Pang, M.S. (1999). Protective truthfulness: the Chinese way of safeguarding patients in informed treatment decisions. Journal of Medical Ethics, Vol.25, No.3, (June 1999), pp. 247-253, ISSN 0306-6800, eISSN 1473-4257.

Surbone, A. (1992). Letter from Italy: Truth Telling to the Patient. JAMA, Vol. 268, No.13, (October 1992), pp. 1661-2 ISSN 0098-7484, eISSN 1538-3598.

Surbone. A. (2004). Persisting differences in truth telling throughout the world. Support Care Cancer, Vol.12, No.3, (March 2004), pp.143-146. ISSN 0941-4355, eISSN 1433-7339.

Surbone, A. (2006). Telling the Truth to Patients with Cancer: What is the Truth. Lancet Oncology, Vol. 7, No. 11 (November 2006), pp. 944-50, ISSN 1470-2045, eISSN 14745488 .

Surbone, A. (2008). Cultural Aspects of Communication in Cancer Care. Support Care Cancer, Vol.16, No.3 (March 2008), pp. 235-240, ISSN 0941-4355, eISSN 1433-7339.

Sun, Y., Z. Li, M. Sun, L. Chang. (2007). A Study of Attitudes of Family Members of Cancer Patients regarding Truth-Telling and Possible Influencing Factors. Chinese Journal of Nursing. No. 6. (in Chinese)

Tang, S. T. and S-Y. C. Lee. (2004). Cancer Diagnosis and Prognosis in Taiwan: patient References versus Experiences. Psycho-Oncology, Vol. 13, No.1, (January 2004), pp. 1-13 ISSN: 1057-9249, eISSN 1099-1611.

Tang, S. T. et al. (2008). Patient awareness of prognosis, patient-family caregiver congruence on the preferred place of death, and caregiving burden of families contribute to the equality of life for terminal ill cancer patients in Taiwan. Psycho-Oncology, Vol. 17, No. 12, (December 2008), pp.1202-1209, eISSN: 1099-1611. 
Tolstoy. L. translated by L. Solotaroff. (1986). The Death of Ivan Ilyich. New York: Bantam Book.

Tse, C.Y., A. Chong, and S.Y. Fok. (2003). Breaking Bad News: A Chinese Perspective. Palliative Medicine Vol.17, No.4 (June 2003), pp. 339-343, ISSN 0269-2163, eISSN 1477- 030X.

Tuckett. A.G. (2004). Truth-Telling in Clinical Practice and the Arguments For and Against: A Review of Literature. Nursing Ethics, Vol.11, No.5, (September 2004), pp. 500-513 ISSN 0969-7330, eISSN 1477-0989.

Wear, S. (2007). Truth Telling to the Sick and Dying in a Traditional Chinese Culture. In S.C. Lee, ed., The Family, Medical Decision-Making, and Biotechnology. pp. 71-82 Dordrecht: Springer. ISBN 978-1-4019-5220-4, eISBN 978-1-4020-5220-0, The Netherlands.

Yixue Yu Zhexue (Editorial Office of the journal Medicine and Philosophy). (2008). Guiding Principles on Truth-telling to and Consent from Cancer Patients. Medicine and Philosophy (Clinical Making Forum Edition) 29 (10): 7-8. (in Chinese)

Zeng, T., Y. Li, Y. Chen, and P. Fang. (2007). An Investigation into the Attitudes of Medical Professional on Disclosing Cancer Diagnoses. Medicine and Philosophy (Clinical Decision Making Forum Edition), 28 (11). (in Chinese). 


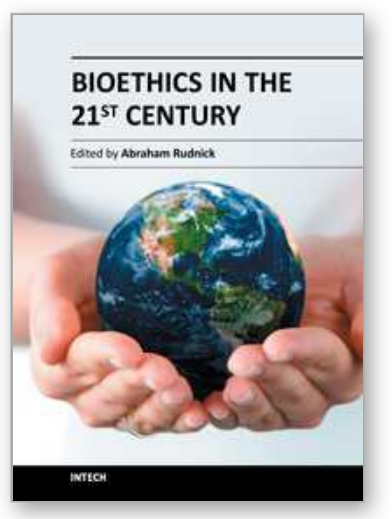

\author{
Bioethics in the 21st Century \\ Edited by Prof. Abraham Rudnick
}

ISBN 978-953-307-270-8

Hard cover, 158 pages

Publisher InTech

Published online 25, November, 2011

Published in print edition November, 2011

Bioethics is primarily an applied ethics of health related issues. It is considered an important guide for health care and its discourses and practices. Health related technology, such as information technology, is changing rapidly. Bioethics should arguably address such change as well as continue to address more established areas of health care and emerging areas of social concern such as climate change and its relation to health. This book illustrates the range of bioethics in the 21 st century. The book is intentionally not comprehensive but rather illustrative of established, emerging and speculative bioethics, such as ethics of mental health care, ethics of nano-technology in health care, and ethics of cryogenics, respectively. Hopefully the book will motivate readers to reflect on health care as a work in progress that requires continuous ethical deliberation and guidance.

\title{
How to reference
}

In order to correctly reference this scholarly work, feel free to copy and paste the following:

Jing-Bao Nie (2011). The "Cultural Differences" Argument and Its Misconceptions: The Return of Medical Truth-Telling in China, Bioethics in the 21st Century, Prof. Abraham Rudnick (Ed.), ISBN: 978-953-307-270-8, InTech, Available from: http://www.intechopen.com/books/bioethics-in-the-21st-century/the-culturaldifferences-argument-and-its-misconceptions-the-return-of-medical-truth-telling-in-chin

\section{INTECH}

open science | open minds

\author{
InTech Europe \\ University Campus STeP Ri \\ Slavka Krautzeka 83/A \\ 51000 Rijeka, Croatia \\ Phone: +385 (51) 770447 \\ Fax: +385 (51) 686166 \\ www.intechopen.com
}

\author{
InTech China \\ Unit 405, Office Block, Hotel Equatorial Shanghai \\ No.65, Yan An Road (West), Shanghai, 200040, China \\ 中国上海市延安西路65号上海国际贵都大饭店办公楼 405 单元 \\ Phone: +86-21-62489820 \\ Fax: +86-21-62489821
}


(C) 2011 The Author(s). Licensee IntechOpen. This is an open access article distributed under the terms of the Creative Commons Attribution 3.0 License, which permits unrestricted use, distribution, and reproduction in any medium, provided the original work is properly cited. 